\title{
Cabildos, élites e intendentes en Chile*
}

\author{
Cabildos, Elites and Intendants in Chile
}

DOI: https://doi.org/10.22380/20274688.954

Recibido: 8 de octubre del 2019

Aprobado: 10 de enero del 2020
LUCRECIA RAQUEL ENRÍQUEZ**

Instituto de Historia de la

Pontificia Universidad Católica de Chile

lenriqua@uc.cl

\section{R E S U M E N}

Se estudia la relación de los intendentes con los cabildos de Concepción, Talca y Santiago en el reino de Chile a fines del siglo XVIII, con el fin de evaluar en ellos cómo las élites locales reaccionaron a los cambios que supuso el nuevo régimen de intendencias a partir de 1786 en el gobierno local y cómo aprovecharon las atribuciones de los intendentes para fortalecerse por medio del conflicto o la colaboración. El tema se analiza con base en la hipótesis de que el nuevo régimen de gobierno abrió nuevas posibilidades a las élites locales de adquirir poder y autoridad en su patria, por su sola instalación y por las relaciones que entablaron con las nuevas autoridades.

Palabras claves: cabildo, ciudad, intendencias, provincia, élites coloniales

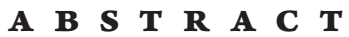

This article studies the relationship between intendants and cabildos in Concepción, Talca, and Santiago in late seventeenth-century
Chile. It analyzes the local elites' response to the changes in the local governance brought by the new intendancy system (1786). Elites

* Este artículo forma parte del proyecto Fondecyt n. ${ }^{\circ}$ I 1707 I 4 , "Los cabildos chilenos desde la reforma de intendencias a la declaración de la independencia en i8r 8 ”, del que la autora es investigadora principal.

** Académica del Instituto de Historia de la Pontificia Universidad Católica de Chile, doctora en Historia de la Pontificia Universidad Católica de Chile y la Université Bordeaux III. Sus temas de interés son el régimen de intendencias, el Real Patronato y las independencias americanas. ORCID: https://orcid.org/0000-0002-7839-2652. 
exploited the intendants attributions to gain power for themselves either through conflict or collaboration. The hypothesis is that the new governance regime gave local elites new opportunities to gain power and authority in their homeland, through both its establishment and the relationships forged with the new authorities.

Keywords: cabildo, town, intendancy, province, colonial elites

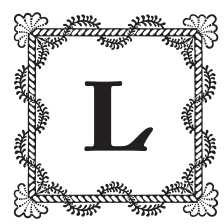

a historiografía no duda que la implantación del régimen de intendencias impactó en la vida de los cabildos americanos. El nuevo gobierno provincial supuso una nueva instancia de poder sobre los municipios, que quedaron relacionados con nuevas autoridades a escala local y supralocal. Sin embargo, hay diferentes posiciones con respecto a la manera en que se produjo este impacto. Una parte de la historiografía coincide en que las relaciones entre cabildos e intendentes fueron conflictivas, ya sea que se las analice contrastando las atribuciones de intendentes y subdelegados o en estudios de casos. El marco global de esta situación lo traza Beatriz Rojas al señalar que el orden jurídico que le dio forma al ordenamiento político colonial se estableció en función de los cuerpos políticos que lo conformaban, "los que ante la concesión de privilegios desarrollaron derechos particulares" (Rojas, Cuerpo político I6); los que, agregamos nosotros, en la mayoría de los casos entraron en conflicto con las facultades concedidas a los intendentes. Para Miguel Molina, el régimen de intendencias afectó la autonomía municipal al superponerse las facultades de intendentes y cabildos relativas a obras públicas, justicia y control de las cuentas municipales, de manera que los cabildos quedaron relegados al gobierno de la vida diaria en la ciudad (Molina 532). También Manuel Lucena considera que uno de los objetivos detrás de la implantación de las intendencias era limitar la autonomía municipal, habida cuenta de que el intendente presidía las reuniones del cabildo, controlaba las finanzas y tenía atribuciones en la causa de policía (Lucena I40). En contraste, para John Lynch en el virreinato del Río de la Plata los intendentes fueron menos abusivos que corregidores y virreyes en las elecciones de los cabildos, por lo que los revitalizaron (Lynch, Administración colonial 192-199). A la misma conclusión arribó John Fischer en el Perú, en el sentido de hacer referencia a la recuperación de la autonomía capitular (Fisher 43I-432). Para José Carlos Chiaramonte, a fines del siglo xvin los cabildos "comenzaron a reavivar sus funciones municipales y a rehabilitar su fuerza política”, en armonía o conflicto con los intendentes (Chiaramonte II7). Según Louisa Hoberman y Susan Socolow, los cabildos 
quedaron bajo el control de los intendentes, cuyas atribuciones en materia fiscal los favorecieron puesto que mejoraron la recaudación de propios y arbitrios (Hoberman y Socolow ir).

Otros autores, como Federica Morelli, señalan que la monarquía se apoyó en el poder municipal para aumentar las rentas fiscales consolidando su poder (Morelli I20). Según Serena Fernández y John Moore, en Perú los cabildos se renovaron a partir del régimen de intendencias, por lo que hubo un resurgimiento del gobierno local (Moore; Fernández 505-522). Para Horst Pietschman, los cabildos se vieron favorecidos por la supresión de corregidores y alcaldes mayores y por la buena administración de los propios, lo que generó "que los notables se sintieran interesados en el gobierno de la ciudad”, pero señala que, en general, los cabildos de la Nueva España obstaculizaron la gestión de los intendentes (Pietschman I86 y 288). Para Luis Navarro García fue al revés: no hubo una oposición de los cabildos a los intendentes (Navarro Io8). Edberto Acevedo considera que en el Alto Perú hubo algunos conflictos entre intendentes y cabildos en materias de policía pero que, en general, los cabildos "no se sintieron perjudicados por la intervención de los intendentes” (Acevedo 80).

Con respecto a los estudios de caso, Romina Zamora analizó la tensa relación entre el intendente y el Cabildo de Tucumán, por negarle el tratamiento de ilustre y por la intervención en las elecciones de alcaldes de la hermandad, de manera que se limitaba la autonomía del cabildo (Zamora 176). José Serrano estudió el conflicto que se desató en Guanajuato entre intendentes y ciudades durante el establecimiento de las subdelegaciones que fortaleció a los cabildos de las cabeceras de intendencia. Graciela Bernal analizó la defensa corporativa de las ciudades de Guanajuato y San Luis de Potosí de sus preeminencias frente a la intendencia y las diputaciones provinciales creadas por la Constitución de Cádiz (Bernal, "Las ciudades" 2, I2). Beatriz Rojas, a su vez, estudió la revitalización de los cabildos de Aguascalientes a partir de la implantación del régimen de intendencias, por el aumento de los propios, la instalación de la junta municipal y diversas medidas de desarrollo económico (Rojas, Las instituciones 278-28I). También reconstruyó el proceso de instalación y revitalización de los cabildos por parte de los intendentes en Zacatecas (Rojas, El municipio 52-60). Graciela Bernal comprobó asimismo que la llegada de las nuevas autoridades de la intendencia a San Luis de Potosí no debilitó al cabildo, que se consolidó como institución (Bernal, "Élites”). El Cabildo de Ciudad Real también se restableció a partir de las intendencias (Gutiérrez). Nuestro estudio sobre los cabildos 
chilenos a partir del régimen de intendencias demuestra que los intendentes propiciaron un proceso de restablecimiento y establecimiento de cabildos, de fin de las suspensiones y de reactivación ${ }^{\mathrm{I}}$. Sin embargo, la discusión plantea$\mathrm{da}$ en los términos expuestos se limita a un análisis relativo al gobierno de la ciudad, a la superposición de atribuciones de intendentes y subdelegados con los cabildos, a la formación de juntas municipales, a los nuevos controles en la recaudación de los propios y arbitrios y a los conflictos que se produjeron en estas materias entre cabildos e intendentes.

Nuestra propuesta va en otra dirección. Abordaremos la relación entre élites cabildantes e intendentes en tres cabildos chilenos: Talca, Concepción y Santiago, analizando cómo usaron los intendentes sus atribuciones en los cabildos y cómo reaccionaron las élites capitulares. La elección de estos tres cabildos estuvo determinada por las fuentes que permiten analizar en ellos el tema. Nos interesa evaluar cómo sus élites se adaptaron al nuevo régimen que estableció otra jerarquía de ciudades y villas, de manera que algunas se convirtieron en cabeceras de intendencias o de subdelegaciones y se fundaron otras subordinadas o cabeceras, por lo que ser parte de los cabildos adquirió un nuevo atractivo para los notables de cada lugar. Por ello, nuestra hipótesis de trabajo es que el nuevo régimen de gobierno abrió nuevas posibilidades a las élites locales de adquirir poder y autoridad en su patria, por su sola instalación y por medio de las relaciones de colaboración o conflicto que entablaron con las nuevas autoridades. Consideramos que si bien hubo cabildos en todas las ciudades y villas, tuvieron particularidades propias en cada lugar (Ponce I09) (Caño I2). Por consiguiente, los cabildos son observatorios de las élites coloniales (Zúńiga 97-IO8).

Como marco general del tema téngase en cuenta que el régimen de intendencias se implantó en Chile en 1786 por medio de la Real Ordenanza de Intendencias del Río de la Plata de 1782. Los corregimientos fueron suprimidos y se instaló un nuevo gobierno distrital: las subdelegaciones o partidos, al frente de las cuales estaban los subdelegados de intendentes. Chile se dividió en dos intendencias.

I Para el estado de la cuestión de este tema, véase Enríquez (21 4-236). 


\section{El Cabildo de Concepción}

Cuando Ambrosio Higgins fue nombrado intendente de Concepción en I786, el cabildo ante el cual juró estaba compuesto solamente de los dos alcaldes ordinarios y el alguacil mayor. Para poner en ejercicio sus facultades propició que se convocara un cabildo abierto en el que propuso ejecutar diversas medidas del artículo 60 de la Real Ordenanza de Intendencias correspondiente a la causa de policía, aprobadas por unanimidad. En reuniones posteriores del exiguo cabildo, Higgins también logró la aprobación de alcaldes de barrio para la ciudad de Concepción y el arreglo de las casas del cabildo (AN, MC, I3).

La actitud decidida del intendente de aplicar el nuevo régimen de gobierno fue más notoria el I. ${ }^{\circ}$ de enero de 1787 , cuando presidió la reunión del cabildo en la que estaban presentes los mismos dos alcaldes y el alguacil y les comunicó que la falta de vocales para efectuar la elección de alcaldes y demás oficios hacía imposible la elección. Por ello, se estaba en la situación de aplicar el artículo 8. ${ }^{\circ}$ de la Real Ordenanza de Intendencias que facultaba a los intendentes a nombrar alcaldes donde no hubiera formal ayuntamiento, por lo cual procedió a nombrar a los alcaldes ordinarios, procurador y alcaldes de la Hermandad para los pueblos subordinados (AN, MC, I5). La necesidad de un ayuntamiento quedó en evidencia en las reuniones posteriores en las que se trataron temas como la toma de conocimiento de decretos del Superior Gobierno sobre pulperías y mesones; el decreto del gobernador intendente sobre el establecimiento de ramo de balanza a favor de los propios de la ciudad y la propuesta del secado de la laguna contigua al paño urbano (AN, $M C$, I6, I7).

Poco tiempo estuvo Ambrosio Higgins en Concepción, en I788 fue nombrado gobernador y presidente de Chile, cargo que llevaba aneja la intendencia de Santiago. Las actas del cabildo de los ańos I788-I790 no se han conservado, por lo que no sabemos con exactitud cómo siguió la relación cabildo e intendente. Queda claro sí que el sucesor de Higgins, Benito de la Mata Linares, propició el remate de los oficios y que confrontados a la opción de que los intendentes hicieran los nombramientos, los patricios locales decidieron incorporarse al cabildo y compraron las regidurías en las que fueron recibidos paulatinamente a partir de I79I (AN, $M C$, I8). Este hecho originó un "Expediente formado a instancia del señor Gobernador Intendente de la Concepción sobre haberse rematado las Varas de aquel cabildo entre Parientes y Hermanos”, presentado ante el Superior Gobierno. En este se señala que se habían pregonado los oficios concejiles del cabildo y que de algunos habían hecho el remate "Don Juan 
de Dios y Don Miguel de Puga, hermanos legítimos, Don Xavier y Don José Manzano que también lo son, y Don José Urrutia y Manzano sobrino de estos" (AN, $C G$, vol. 994).

Quiere decir lo anterior que antes de la llegada de los intendentes el cabildo estaba paralizado, sin miembros, y que a partir de la llegada del intendente Higgins empezaron los nombramientos para que el cabildo se conformara. Los notables locales respondieron instalando una red familiar que remató los oficios. De la Mata Linares argumentaba que no había prohibición expresa en las leyes del reino que impidiera que en un mismo regimiento hubiera "Hermanos o Parientes dentro del cuarto grado", pero eran evidentes los inconvenientes que esto acarrearía, favoreciendo el espíritu de partido y la formación de parcialidades. Citaba las leyes de Indias que impedían que miembros de una misma familia, colegio y pueblo formaran parte de una Real Audiencia, así como una real cédula que prohibía que hubiera parientes en las oficinas de la Real Hacienda. También la Ley 5, título io del libro 4 de la Recopilación de Leyes de Indias impedía que en los regimientos hubiera padres e hijos, hermanos, cuñados, suegros y yernos. Asimismo, los intendentes habían recibido el encargo de impedir que en los cabildos hubiera monopolios y alianzas para que los capitulares desempeñaran sus obligaciones con desinterés. Recordaba que el artículo 35 de la Ordenanza de Intendencias había puesto "al cuidado de los regidores" el manejo de los propios y arbitrios. Por ello, señalaba que "el buen orden y gobierno de este regimiento exigen que no se admita en él la concurrencia simultánea de Parientes en los grados insinuados", y pedía al presidente que resolviera. El fiscal opinó que se debían escuchar los descargos de Francisco Javier Manzano, quien fue notificado al igual que el resto de sus parientes, y se defendió diciendo que no había "prohibición específica para que entren en un cabildo muchos parientes", pero no le convenía "entrar con desagrado o contra el dictamen de aquel Jefe" porque pensaba retirarse a vivir en la ciudad de Santiago, por lo que pedía al presidente que se aceptara el desistimiento de su parte del remate de la vara de alcalde provincial y que procediera actuando en justicia. El resto de los parientes no comparecieron y se les consideró en rebeldía. Juan de Dios Puga alegó que no había ley en el reino que lo impidiera, a diferencia de lo que ocurría en los casos de la Real Audiencia y la Real Hacienda, por lo que los remates eran legítimos (AN, $C G$, vol. 994, ff. I2, I4).

No se conservó el acta de elección del I. ${ }^{\circ}$ de enero de i79I. Las actas comienzan a partir del mes de mayo, dejando asentado el recibimiento de tres regidores: Manuel de Puga y Figueroa, Juan de Arrau y José Martínez, quien 
además era el subdelegado del partido de Puchacay. Solamente Puga estaba emparentado con la cuestionada red familiar (AN, $M C)$.

Las actas del cabildo del año I792, señalan que hubo elecciones el I. ${ }^{\circ}$ de enero, pero no concurrieron los regidores. Se eligió alcalde de segundo voto porque el regidor más antiguo ejercía como alcalde de primer voto (AN, MC, I9). Ese año, la Junta Superior de Real Hacienda determinó que se pusiera en posesión a quienes habían rematado las varas y el fiscal lo ordenó porque "estaba removido el impedimento a causa de renuncia de otros" (AGI, CH, 297); es decir, que el intendente había logrado desarticular la instalación de la red familiar como tal porque algunos habían renunciado a sus varas. Veamos cómo siguió el caso.

En 1793 la vara de depositario general fue rematada por Juan de Dios Puga, uno de los cuestionados en 1790 por el intendente, sumando dos miembros de esa familia en el cabildo. En junio de 1793 consta en el acta que el intendente Mata Linares se quejó de la indolencia de los miembros del cabildo, dado que asistían a las reuniones semanales solamente el asesor letrado y los dos alcaldes. Por ello, mandó que hubiera ayuntamiento todos los viernes, al que era obligatorio que asistieran "todos los regidores, depositario general alguacil mayor y procurador general, y demás individuos que componen el cabildo como no tengan motivo legítimo para faltar" (AN, $M C$, 33), lo que ocurrió regularmente desde entonces.

Una nueva red familiar se instaló en 1794 compuesta por las familias $\mathrm{Pu}$ ga y Figueroa. Las elecciones de alcaldes de segundo voto y procurador de 1795 terminaron en un empate, por lo que la decisión pasó a manos del gobernador intendente Luis de Álava, quien salomónicamente eligió a uno de los votados por cada grupo (AN, $M C$, 35 y 36). Fue entonces cuando el presidente Ambrosio Higgins elevó el caso de la instalación de redes familiares en los cabildos al Consejo de Indias, relatando la situación de I790-I791 y la discordia dentro del cabildo en las elecciones de alcalde y procurador. A este respecto señaló que por ello se acordó "consultar a SM solicitando para lo sucesivo decisión terminante sobre el caso en general”. El caso se trató en la Secretaría del Perú, como consta en el "Expediente sobre la duda que propone el Presidente de Chile acerca de si pueden servirse simultáneamente por hermanos y parientes dentro del cuarto grado los oficios concejiles". El fiscal del Consejo consideró que el caso "necesita examinarse con respecto a las dos Américas" (AGI, CH, 297), lo que quiere decir que pasaba a ser examinado por los fiscales de las secretarías del Perú y de la Nueva España. 
El fiscal del Perú respondió que no debía "alterarse de modo alguno la práctica y costumbre de admitir para los oficios concejiles a los parientes dentro del cuarto grado". En su criterio, no había leyes que lo prohibieran y en los pueblos todos los sujetos con caudal estaban emparentados. Si se los excluyera en cuarto grado de parentesco del acceso a los oficios de república, por ser vendibles y renunciables, no se encontraría quién los comprara, lo que conllevaría un quebranto de la Real Hacienda. Proponía entonces que se privara de voto "a todos los parientes que hubiese dentro del cuarto grado en las elecciones en que fuesen propuestos alguno de ellos, y en los demás asuntos en que tuviesen interés particular", para remediar el daño que pudiera ocasionar la alianza entre parientes.

El fiscal de la Nueva España señaló que consideraba "muy justa” la objeción del intendente de Concepción de que no se rematasen los oficios concejiles "en hermanos o parientes de los que componían el Ayuntamiento", porque la sangre formaba partidos, sobre todo si esos sujetos administraban justicia o manejaban caudales públicos. Opinaba que se podía extender a los capitulares de los cabildos la Real Cédula de 1775 y que el argumento del fiscal del Perú sobre no encontrarse sujetos que compraran los oficios por ser todos parientes en los pueblos, estaba previsto en las leyes que preveían "que los ministros de Real Hacienda en la venta de oficios miren por el acrecentamiento de esta, pero atendiendo al bien de la república, y que en las personas de los compradores se encuentren todos los requisitos necesarios para el mejor desempeño". Señaló que los oficios subastados se habían rematado de buena fe y según la práctica habitual, por lo que se debía respetar el contrato. Proponía que en adelante los oficios concejiles del Perú "no se rematen en sujetos que tengan parentesco de consanguinidad, o afinidad en los grados, que quedan insinuados, y especifica la Real Cédula de 20 de enero de 75 , pues de este modo queda uniforme la práctica de ambas Américas" (AGI, $\mathrm{CH}, 297$ ).

Las elecciones del I. ${ }^{\circ}$ de enero de 1796 se realizaron en presencia del asesor letrado y participaron todos los miembros del cabildo. Con excepción del regidor José María Martínez, el resto votó por el mismo candidato a alcalde de segundo voto y de procurador. Pese a que Martínez protestó de nulidad de la elección, el gobernador intendente confirmó al elegido (AN, MC, 4I).

En las elecciones del I. ${ }^{\circ}$ de enero de 1797 resultaron elegidos a coro, como alcalde de segundo voto Francisco Xavier Manzano, miembro de la red familiar de 1790, y como procurador general Victorio Pantoja. Sin embargo, el gobernador intendente no las confirmó y designó como procurador a Manuel 
de Unzueta y como alcalde de segundo voto a Alejand ro de Urrejola, decisiones que fueron confirmadas por el presidente Marques de Avilés (AN, MC, 5I y 52).

El I. ${ }^{\circ}$ de enero de 1798 tres de los regidores del cabildo eran miembros de la familia Puga. Por aclamación eligieron a uno de ellos, Juan de Dios Puga, como procurador y a Juan Quintana como alcalde de segundo voto. Nuevamente, el gobernador intendente intervino en la elección rechazando al procurador electo y nombrando al abogado José Antonio Prieto, aunque confirmó al alcalde de segundo voto (AN, $M C, 55)$.

A partir de entonces el cabildo entró en un ritmo estable de elecciones el primer día de cada año, que fueron confirmadas por el gobernador intendente, hasta las elecciones del I. ${ }^{\circ}$ de enero de 1806 en las que las votaciones estuvieron divididas y el asesor letrado zanjó la disputa nombrando a los alcaldes de primer y segundo voto y manteniendo como procurador al elegido el año anterior. Esto último originó una protesta ante el intendente Álava, que fue acogida, por lo que procedió a hacer el nombramiento en otra persona (AN, $M C, 67$ y ss.).

\section{La familia de la Cruz Bahamonde en el cabildo y la subdelegación de la villa de Talca}

Los de la Cruz Bahamonde estaban ya instalados en el Cabildo de Talca, su patria, cuando la implantación en Chile del nuevo régimen de intendencias cambió la vida de esta familia en dos sentidos. Por un lado, Talca pasó de ser cabecera de corregimiento a cabecera de subdelegación. Por otro, Ambrosio Higgins, amigo de la familia, fue nombrado intendente de Concepción y posteriormente presidente de Chile e intendente de Santiago y, finalmente, virrey del Perú, convirtiéndose en un mediador extraordinario que les franqueó el acceso a la vía reservada de Indias. En efecto, el haber logrado el control del Cabildo de Talca a mediados de la década de 1780 por sí solo no explica, sin duda, que los de la Cruz Bahamonde se insertaran con tanta certeza y precisión en el gobierno local. La amistad con Ambrosio Higgins fue lo que les permitió dar el salto a un cargo de poder en el gobierno de la monarquía, cuando Higgins nombró a Vicente de la Cruz subdelegado del Maule en 1788 con la siguiente recomendación que nos recuerda sus medidas en Concepción: 
Deberá VM por constante sistema de su manejo el portarse con absoluta imparcialidad, sin adhesión de familia, ni otras conexiones, de manera que no dé motivo de queja ni recurso alguno, para evitar mis resoluciones, que serán precisas en caso de haberlas, para mantener la paz y armonía de los pueblos y habitantes de su jurisdicción. (AN, $C G$, vol. 778, "Documentos de Ambrosio Higgins I788")

Nicolás de la Cruz, instalado en Cádiz, se dedicaba al comercio y tramitaba ante la Cámara de Indias las pretensiones de su familia, amigos y muy especialmente de Ambrosio Higgins. Sin embargo, la base de la acción familiar fue el cabildo desde el cual impulsaron una política de engrandecimiento de la villa y de desarrollo del partido. En I79I el cabildo elevó al Superior Gobierno la petición de que el rey le concediera el título de ciudad a Talca. Como explica Francisco Javier Vela, la distinción entre los diferentes tipos de localidades se fundaba en las competencias jurisdiccionales (Vela 196).

Talca, fundada como villa en I742, su jerarquía cambió al convertirse en cabecera de subdelegación, lo que sin duda estuvo en la base de la solicitud a la Cámara del título de ciudad. Entre los méritos que el cabildo expuso estaba el que los habitantes del Maule habían sido los primeros auxiliares de la Corona contra los araucanos, puesto que habían derrotado a Lautaro, así como en la contención de los pehuenches, ya que habían conservado el territorio para la monarquía. Se presentaban como una porción noble de población, reunida en vida civil y sociable a partir de la fundación de la villa, españoles de sangre limpia, acaudalados, que colaboraban con el mantenimiento de conventos y curatos.

En 1794 Higgins elevó al rey la petición que fundamentó en las bondades del clima, la feracidad de la tierra, la presencia de minas de oro, el comercio interior y con España y la nobleza de la población. Además, señaló que "el Ayuntamiento completo de todas sus plazas resultaba de personas decentes, bien instruidas", había cooperado "con celo y eficacia desde su establecimiento con los corregidores a darle una Policía que la acercaba a la capital y hacía igual si no superior a la de la Concepción”, y que desde que le solicitaran apoyo para elevar al rey la petición habían construido edificios, iglesias, casas del cabildo y cárcel, y, además, se habían instalado a vivir vecinos hacendados, por lo que el adelantamiento de la villa facilitaría que se reconcentraran en ella los habitantes del partido "que me consta desdeñan avecindarse en el por faltarle esta denominación y que con ella se establecerían formando un Pueblo considerable", cuya industria beneficiaría al resto de los "vivientes de campaña". Se favorecería 
también la fundación de una villa en la desembocadura del río Maule que desarrollaría el comercio a Valparaíso y Lima. Afirmaba también que había escuelas de primeras letras y latinidad y que Talca era ya un pueblo ilustre por ser la patria del abate Molina ("El cabildo y el ayuntamiento" 374-38I).

Desde Cádiz, Nicolás de la Cruz seguía la tramitación en el interior del Consejo de Indias. A su hermano Juan Manuel le escribió que su amigo el agente de negocios Núnez, le había dado esperanzas de pronto despacho y cuidaba de que los honores conseguidos se atribuyeran al cabildo. Por eso, el título se pondría en vitela "para que se archive en el Libro de Cabildo de Talca. Del escudo haré sacar aquí una copia en mármol y se lo enviaré a la nueva ciudad de regalo, para que lo pongan en las casas Capitulares" (Martínez 6I). Una vez obtenido, la sed de honores de Nicolás de la Cruz persiguió el fin, según escribió a su hermano Vicente, "de conseguirle también a Talca, en virtud de sus méritos los títulos de muy noble y muy leal", aunque el principal objetivo era "pensar en el establecimiento del colegio en la nueva ciudad", puesto que de la "educación de sus hijos [pendía] la felicidad de los hombres" para que los jóvenes fueran aptos para la carrera "política, militar, eclesiástica o comerciante". De tal beneficio gozarían los vecinos de ese partido y de los cercanos. Estaba dispuesto a hacer un importante desembolso, pero sugería a su hermano que todos los vecinos contribuyeran a ello, aunque "Voy puesto in capite en esa lista", y que cuando se dispusiera de la cifra debía juntarse "el Cabildo y propone el pensamiento al jefe para que lo apruebe" (Martínez Ioo). "El jefe” era el apodo que Nicolás de la Cruz le daba a Ambrosio Higgins. Todo, todo, estaba calculado para acrecentar el lustre de la ciudad, de la familia y el suyo propio. Incluso proyectaba que el cabildo podría aspirar al nombramiento de muy magnifico, título honorífico que significaba "grande, excelente, esplendido, liberal y grandioso" ("Muy magnífico” 1734). Según Covarrubias, estaba en desuso desde principios del siglo XVII (Covarrubias 532).

El origen de la riqueza y la figuración social de la familia se asentaba en el engrandecimiento de su patria, y para mantener ese prestigio y poder era clave el desarrollo y engrandecimiento no solo de la ciudad, sino también del partido que controlaban. La posibilidad llegó por contar con un extraordinario mediador, Higgins, como el mismo Nicolás desde Cádiz lo reconoció a su hermano:

Tú sabes mejor que nadie mi patriotismo; pues desde el momento que supe en Madrid el año de 87 el ascenso de don Ambrosio O'Higgins a la Capitanía General de ese reino, te envié las instrucciones para tratar de constituir en ciudad a nuestra patria. Luego con la noticia que me 
comunicó dicho jefe de que te iba a nombrar subdelegado de esa provincia, te dirigí un papel con varias advertencias y reflexiones para proporcionarle las mayores ventajas en su agricultura, industria y comercio; y también para el arreglo de la Policía de Talca su capital. Después no he cesado de inducirte las mismas ideas, extendiéndolas hasta la erección de un Colegio, cuyo establecimiento te he recomendado con el mayor ahínco, hasta remitirte una lista que sirva para anotar los contribuyentes para la formación de sus fondos, poniéndome in capite con un donativo de dos mil pesos y además todos los libros clásicos. Otras varias ideas me ocurren que comunicar al Ilustre Ayuntamiento, interesantes al país; pero suspendo por ahora, hasta saber que tiene evacuadas las que tiene entre manos de cárcel, hospital, fuentes, refacción de iglesias, y el colegio; porque conviene dar fin a unas para emprender otras. En fin como decano de ese cabildo me harás el honor de leer en la junta, esta carta, manifestándoles con toda la sensibilidad de mi corazón el singular interés con que miro por los adelantamientos de la patria, para que todos queden prevenidos que tienen aquí un patricio capaz de desempeñarles en sus buenas ideas, y para que no se detengan jamás de proponerme sus ocurrencias contando conmigo, como tú, para todo. (Martínez II4-II5)

Desde Cádiz, Nicolás planeaba el desarrollo de la ciudad y del partido por medio del acrecentamiento del comercio, pero también sentía que faltaba una recompensa a sus desvelos. De hecho, le escribió a su hermano Vicente lo siguiente: "me ocurrió el bello pensamiento de poder ser remunerado en algún modo de la patria", no por interés "sino por conservar indeleble en nuestra familia un rasgo de su generosidad que la hará honor, y que también acreditará en lo venidero mis servicios y patriotismo". Proponía que la ciudad le retribuyera sus servicios obsequiándole "el empleo de Regidor haciendo rematar a mi nombre uno de los doce que en virtud de la cédula de erección se han de poner a subasta”. Pedía a su hermano que propusiera al cabildo que el costo del remate fuera tomado de los propios de la ciudad y que una vez que el presidente informara al rey para su confirmación, "se me conceda el privilegio de nombrar Teniente: de este modo disfrutaré de la satisfacción del nombramiento; y de la propiedad del oficio, porque se nombrará a quienes vuestras mercedes quieran de Teniente" (Martínez iı6). Esta petición a su hermano Vicente fue acompañada del envío al Cabildo de Talca de los reales despachos de la concesión del título de ciudad 
e informaba que estaba pretendiendo "para la nueva ciudad los honores de muy noble y muy leal” (Martínez ir6-iı7).

Los honores de ese nuevo título fueron concedidos en I796, luego de lo cual Nicolás de la Cruz pidió al rey la aprobación de un nuevo escudo para la ciudad de Talca, que le fue concedido y que envió desde Cádiz para que fuera puesto en las casas capitulares del cabildo, que la ciudad "podrá usar donde guste; en despachos, sellos” (Martínez I76). Inmediatamente, impulsó dos nuevos proyectos para la ciudad. Primero, el establecimiento de "una feria en Talca para fomentar su comercio y población”, para lo cual había escrito una carta y memoriales que Vicente debía hacer firmar a todos los miembros del cabildo para ser presentado al presidente, con el fin de que hiciera el informe y lo enviara "por la vía reservada a la Corte, en donde trataré de que se conceda por Su Magestad la gracia” (Martínez 134) para que Nicolás moviera sus contactos. La red fue otra vez puesta en marcha: Nicolás y Vicente de la Cruz - cabildo Ambrosio Higgins. Segundo, el establecimiento de un colegio para el cultivo de los talentos de los jóvenes que diera a conocer en América y Europa lo que producían y "su comercio tomaría mayores aumentos" (Martínez I43).

También insistió sobre su nombramiento como regidor otorgado "en reconocimiento por ese Cabildo de los servicios que hago al país” (Martínez 25I). Llegado el día de la elección de alcaldes en I797, el Cabildo de Talca lo eligió, pero como alcalde de segundo voto, para "remunerar en parte los muchos favores que le debe particularmente el que acaba de recibir de erigirse en ciudad esta villa”. El nombramiento quedó pendiente de la confirmación del presidente y como las leyes del reino no permitían que fueran elegidos para los oficios concejiles sujetos ausentes, dado que debían ser ejercidos por propietarios y no por sustitutos, el presidente mandó que se eligiera a otra persona (Adunka y Muñoz 250 y 252). La suerte de los De la Cruz cambió por la llegada del nuevo presidente de Chile, Marques de Avilés, ante quien cayeron en desgracia y no apoyó más las obras que la familia impulsaba a través del cabildo.

\section{Criollos y españoles en el Cabildo de Santiago}

Con motivo de la muerte del gobernador presidente de Chile en 1787, asumió el gobierno interino el regente Tomás Álvarez de Acevedo, quien se convertía 
en presidente de la Audiencia, capitán general e intendente de Santiago. La gobernación había recaído en la Real Audiencia (AGI, $\mathrm{CH}$, 283, "Dictamen del Fiscal del Consejo de Indias, 7 de febrero de 1789 ”). En estas circunstancias, se desarrolló un fuerte enfrentamiento entre el regente intendente y el Cabildo de Santiago a raíz de la renuncia del alcalde de segundo voto, Juan de Morandé, elegido el $\mathrm{I}^{\circ}{ }^{\circ}$ de enero de $\mathrm{I7} 88$, que fue presentada ante el intendente, quien procedió a nombrar a Domingo Díaz de Salcedo y Muñoz en su lugar, justificándolo en las facultades que le estaban concedidas en la Real Ordenanza de Intendencias. Entonces, el alcalde provincial de la Santa Hermandad presentó un recurso ante la Real Audiencia por considerar que se habían arrollado los derechos del cabildo. Interesa a nuestro tema exponer cómo actuó cada parte.

Los hechos los conocemos, inicialmente, porque fueron informados por Álvarez de Acevedo con testimonios por la vía reservada de Indias a la Secretaría de Gracia y Justicia, con el fin de solicitar la habitual confirmación real de los empleos de cabildo. Expuso que Juan de Morandé había renunciado desde su hacienda de Lay Llay al empleo de alcalde ordinario de segundo voto para el que había sido elegido por el cabildo, argumentando que perjudicaba sus intereses y haciendo valer la excepción que le competía por ser coronel de milicias, según el artículo $3 .^{\circ}$ de la Ordenanza de Intendencias de Cuba. Álvarez de Acevedo señala que aceptó la renuncia porque la argumentación le pareció adecuada, pero que también vio en ello la posibilidad de cumplir con el artículo i7 de la Instrucción de Intendentes relativo a cortar "un antiguo, y sedicioso empeño que sostenían algunos capitulares, de no elegir para estos oficios honoríficos de Justicia, y Concejo, a individuos oriundos de esa Península”, aunque estuvieran avecindados en la ciudad. Y, como había muchos meritorios e idóneos, ello causaba odiosidades y se formaban parcialidades de familias con perjuicio de la causa pública. Por esto, había nombrado para que sirviera dicha alcaldía a Domingo Díaz de Salcedo, ascendido poco tiempo antes a coronel del Regimiento de Milicias del Rey, usando las regalías para hacer esas provisiones "en que se hallaba esta Presidencia” por el uso de estas que habían hecho sus antecesores y porque desde 1768 no se había elegido vecino europeo como alcalde. Agregaba que había hecho incluir en los autos que enviaba el recurso que José Miguel de Prado, alcalde provincial de la Hermandad, había interpuesto ante la Real Audiencia, en el que afirmaba, equivocadamente, que la renuncia de Morandé no era absoluta y que el cabildo le había concedido un periodo de tres meses para que fuera a recibirse, lo que contradecía una carta posterior que Morandé le había enviado a raíz de la controversia sobre ese punto. De manera errada, 
según el intendente, Prado entendía que al renunciar Morandé volvía al cabildo la facultad de elegir alcalde y no era legal el nombramiento hecho por él. Ante estos sucesos, pedía al rey que aprobara su designación (AGI, $\mathrm{CH}, 283$, "Carta de Tomás Alvarez de Acevedo, Regente de la Audiencia de Chile, Capitán General e Intendente de Santiago, a Antonio Porlier, Ministro de Gracia y Justicia de Indias del 29 de abril de I788").

Por su parte, el 7 de junio de 1788 , el alcalde provincial José Miguel de Prado le envió una carta a Antonio Porlier, el ministro de Gracia y Justicia de Indias, sobre lo acontecido y le solicitó que elevara "la noticia a la Real consideración", a fin de que se suspendiera lo obrado por el intendente interino de Real Hacienda "y repusiera al Cabildo en el uso de sus facultades de que se le ha despojado". En lo sustancial señala que Morandé hizo renuncia del empleo desde su hacienda en carta dirigida a Antonio Tadeo de los Álamos, escribano interino del ayuntamiento, que fue quien le había comunicado la elección "pidiendo en subsidio de no haber lugar a la renuncia, el plazo de tres meses en que finalizaban las faenas que tenía entre manos podía regresar a tomar posesión del cargo". Señalaba que el presidente intendente procedió a hacer un nombramiento, aunque estaba en el ánimo de los capitulares otorgar a Morandé el plazo pedido. Cuando se presentó Díaz de Salcedo a ser recibido, algunos capitulares manifestaron su contradicción y la vulneración de los derechos del cabildo al que tocaba todo lo relativo a los oficios, pero otros por consideraciones políticas y temor a esa autoridad "no quisieron sostener las facultades del cabildo" y el nombrado "fue admitido, y se le dio la posesión del empleo". Sin embargo, para no estar incluido en la responsabilidad de lo actuado por los demás que "no protestaron, ni salvaron sus votos en el libro secreto de acuerdos”, ocurrió como alcalde provincial y regidor perpetuo a la Real Audiencia aduciendo nulidad de todo lo obrado, querellándose de despojo por haber interferido en las facultades del cabildo fundadas en las leyes y presentando testimonio de las actas capitulares. El fiscal conceptuó legítimo el recurso y la Audiencia pidió al subdelegado de la intendencia de la ciudad que le remitiera testimonio de los votos y actas capitulares y de los acuerdos tomados que se relacionaran con la elección y renuncia de Morandé y la recepción de Díaz de Salcedo. Sin embargo, el subdelegado no remitió el testimonio de los votos, en el que constaba quiénes y cuántos habían sido contrarios a que asumiera Díaz de Salcedo para que se usara contra las providencias del regente. El recurso no continuó por "su pobreza y el no haber encontrado abogado que le quisiera proteger", por temor al regente. Por eso, había implorado al fiscal que "como encargado de 
celar la observancia de las leyes, promoviera el cumplimiento de las que hablan de las facultades de los ayuntamientos, y sus privilegios".

Requerido por la Audiencia, el escribano de la intendencia Antonio de los Álamos había dado testimonio de que el expediente de la renuncia de Morandé estaba compuesto solo de la carta del renunciante, escrita al cabildo que entregó al regente, quien le incorporó el decreto de la admisión, la comunicó al cabildo y procedió a nombrar a Díaz de Salcedo. De este modo concluía el expediente. Por su parte, el regente contestó al Tribunal que no hubo ninguna apelación en su juzgado sobre lo obrado y que tuvo noticia de que el alcalde provincial

[...] resentido de que su nombramiento hubiera recaído, en vecino europeo, intentara mover litigio sobre la validación, no creyó hubiera letrado que pudiera fundarlo en derecho ni que se le admitiese en la Real Audiencia sin este requisito, y sin que lo dedujese primero en su juzgado y precediese la respectiva substanciación, con el electo, y el cabildo.

El regente había dado cuenta al rey de lo actuado y conceptuaba que no estaba el asunto "en estado de remitirlo a la Audiencia”. Entonces, José Miguel Prado, portando la carta de renuncia de Morandé, se presentó ante el Tribunal y pidió que este hiciera que Morandé reconociera la carta "bajo juramento" y que se insertara en el testimonio que había pedido para ocurrir a Su Majestad. Morandé declaró ante el fiscal que la carta era suya. Por eso, Prado señalaba que la relación de los hechos mostraba que su procedimiento en el asunto "ha sido legal y atentado el del Regente Intendente". Lo que lo animaba en la causa "es defender los derechos del cabildo" y no que hubiera recaído la alcaldía en vecino europeo, y que por derecho Morandé debió haber renunciado en manos del cabildo "de donde dimanó su elección", porque los cabildos deben conocer las causas fundadas que hagan legítimas las renuncias. Sin embargo, si se hubieran guardado las formas, tampoco el regente intendente hubiera podido mezclarse en el asunto porque las leyes de Indias conferían a los cabildos las facultades de elegir alcaldes ordinarios, y la Real Ordenanza de Intendentes los autorizaba a hacerlo en las "ciudades, villas y lugares de espańoles que no hubiere" formal ayuntamiento. Esto ligaba las manos a los intendentes para crear alcaldes donde hubiera cabildos que los pudieran elegir, por lo que el regente había procedido sin jurisdicción. Además, el pretexto del uso y la costumbre no podía argüirse porque la intendencia estaba recién instalada y ese era el primer caso que se presentaba, por lo que no debía servir de perjudicial ejemplo para "perturbar a los ayuntamientos en el ejercicio de las funciones de su ministerio”. Pedía al rey 
"que se deshaga el agravio al cabildo" (AGI, $\mathrm{CH}, 283$, "Carta de José Miguel Prado, Alcalde Provincial de la Santa Hermandad del Cabildo de Santiago de Chile, a Antonio Porlier, Ministro de Gracia y Justicia de Indias del 29 de abril de I788”).

El caso pasó al Consejo de Indias el 29 de octubre de I788. La exposición del fiscal resume lo que ya hemos expuesto, pero agrega que según el expediente recibido desde Chile, Morandé había sido elegido por todos los votos el I. ${ }^{\circ}$ de enero y que Álvarez de Acevedo había confirmado la elección; que Díaz de Salcedo había sido recibido solamente por cinco de los trece capitulares el día 2I de enero; que la Real Audiencia le pidió al regente que le remitiese los autos de lo obrado, pero contestó que no debía remitirlos y los mandó archivar en la Intendencia para que estuvieran a disposición del siguiente intendente; ante esto el alcalde provincial pidió testimonio del expediente que le fue dado.

El Consejo fue del parecer que la renuncia de Juan de Morandé en Tomás Álvarez de Acevedo "fue contra la disposición de las leyes y también el nombramiento de alcalde que practicó en Don Domingo Díaz de Salcedo”, y que Morandé debió haber renunciado en el cabildo para que los capitulares pasaran a elegir en la forma acostumbrada otro sujeto que ejerciera el empleo de alcalde, "pues no le dio derecho, o facultad al Presidente interino para admitir la renuncia de Morandé, y nombrar a Díaz de Salcedo el artículo octavo de la Real Instrucción de Intendentes en que da facultad de confirmar las elecciones de oficios que hiciesen los ayuntamientos”, revocando las leyes de Indias que conferían esta facultad a virreyes, gobernadores y audiencias. Por lo anterior, se desaprobaba "el procedimiento de Acevedo para que no sirva de ejemplo en lo sucesivo en casos de igual naturaleza" y que como había pasado un año desde que fuera elegido Díaz de Salcedo y si se reponían las cosas al estado del momento del nombramiento habría nuevos disturbios por la nulidad de los actos de alcalde, "He resuelto, subsanarle, y dar por válida la jurisdicción, mandando que en lo sucesivo en casos iguales se hagan las renuncias de los oficios de Ayuntamiento en manos de él, y que admitiéndolas procedan a nueva elección en la forma dispuesta por las leyes" (AGI, CH, 283). El 8 de mayo de 1789 el rey mandó al presidente intendente de Chile, a la Real Audiencia y al Ayuntamiento de Santiago que guardaran y cumplieran su real resolución. 


\section{Conclusiones}

Nos propusimos en este artículo evaluar en los casos de los cabildos de Concepción, Talca y Santiago la relación de las élites capitulares con los intendentes. En cada cabildo, según las circunstancias propias, esas relaciones fueron distintas. En Concepción los intendentes nombraron miembros del cabildo y usaron el derecho de confirmación para anular elecciones. En el primer caso, Ambrosio Higgins lo hizo para que hubiera formal ayuntamiento, de la Mata Linares y Álava usaron esa facultad luego de no confirmar elecciones hechas por los capitulares, con el fin de impedir que redes familiares se hicieran con el control del cabildo. Sin embargo, esto no fue posible de impedir porque no había ningún medio legal que lo prohibiera, como quedó claro al denunciar estas redes a la Presidencia y al Consejo de Indias. Es decir, que ante la imposición de los intendentes de que hubiera un cabildo que funcionara, la élite local respondió instalando una red familiar que no fue posible desarticular. En total contraposición a lo ocurrido en Concepción, en el Cabildo de Talca el presidente intendente Ambrosio Higgins permitió que la familia de la Cruz continuara controlando el cabildo y nombró a un miembro de esta como subdelegado, pero subordinando a su recomendación ante la monarquía todas las políticas impulsadas por el cabildo. Finalmente, en el caso del Cabildo de Santiago, el intendente justificó el único nombramiento que hizo en la intención de instalar a un peninsular como alcalde, lo que no fue avalado por la Cámara de Indias al confirmar que el nombramiento había sido contra las leyes. En Concepción y Santiago los intendentes enfrentaron a las élites locales usando sus facultades de confirmar o rechazar las elecciones de alcaldes para debilitarlas e intentando terminar con redes de familia y mayorías criollas en el interior de los cabildos, sin éxito por no tener el aval legal necesario. De esta manera, las élites locales salieron fortalecidas ante los intendentes. 


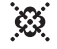 \\ B I B L I O G R A F í A}

\section{I . F U E N T ES PRIMARIAS}

\section{A. Archivos}

Archivo General de Indias, Sevilla, España (AGI).

Chile $(\mathrm{CH})$. $283,297$.

Archivo Nacional, Santiago, Chile (AN).

Capitania General ( $C G)$.

$778,994$.

Municipalidad de Concepción (MC).

Volumen I.

\section{B. Impresos}

"El cabildo y Ayuntamiento de la villa de San Agustín de Talca pide se le conceda el título de ciudad". Revista Chilena de Historia y Geografía, tomo LIII. n. ${ }^{\circ}$ 57, abril-junio 1927, pp. 373-385.

“Muy magnífico”. Diccionario de Autoridades, Real Academia Española, tomo IV, I734.

\section{I F U E N T ESSECUNDARIA S}

Acevedo, Edberto. "La causa de policía”. Estudios sobre la real ordenanza de intendentes del Rio de la Plata. Buenos Aires: Instituto de Investigaciones de Historia del Derecho, I995, pp. 43-82.

Adunka, Michelle L. y Juan Guillermo Muñoz. “Actas del cabildo de la villa de San Agustín de Talca (Reino de Chile, I759-I8I5)”. RIVAR, vol. 2, n. ${ }^{\circ}$ 5, 2015, pp. 160-270.

Bernal, Graciela. “Elites, estrategias y alternativas políticas. El cabildo de San Luis de Potosí, I786-I808”. Ayuntamientos y sociedad en el tránsito de la época colonial al siglo XIX. Reinos de Nueva España y Guatemala, de Laura Machuca Gallegos. México: Publicaciones de la Casa Chata, 2004, pp. 99-II7. 
---. "Las ciudades de San Luis Potosí y Guanajuato en defensa de su preeminencia, I786-i 82 I". Rubrica Contemporanea, vol. 8, n. ${ }^{\circ}$ 15, 2019, pp. 5-24.

Caño Ortigosa, José Luis. Los cabildos en Indias. Un estudio comparado. Corrientes: Moglia Ediciones, 2009.

Chiaramonte, José Carlos. "Modificaciones del pacto imperial”. De los imperios a las naciones: Iberoamérica, coordinado por Antonio Annino, Luis Castro Leiva y François-Xavier Guerra. Zaragoza: Iber Caja, 1996, pp. 85-116.

Covarrubias, Sebastián. Tesoro de la lengua castellana o española. Madrid: Luis Sánchez impresor del Rey, I6II.

Enríquez, Lucrecia. "El despertar de los cabildos chilenos a fines del siglo XviII". Temas Americanistas, n. ${ }^{\circ}$ 42, 2019 , pp. 214-236.

Fernández, Serena. "Iniciativas renovadoras en los cabildos peruanos a fines de la época colonial”. Revista de Indias, n. ${ }^{\circ}$ 193, 1991, pp. 505-522.

Fisher, John. "The Intendant System and the Cabildos of Perú (1784-1810)". The Hispanic American Historical Review, n. ${ }^{\circ} 49$, I969, pp. 430-453. DoI: https://doi. org/10.4324/978042943278I-2I.

Gutiérrez Cruz, Sergio Nicolás. "La provincia chiapaneca entre la Monarquía y la república. Conflictos jurisdiccionales y territoriales en una época de cambios: 1744-1833". Ayuntamientos y sociedad en el tránsito de la época colonial al siglo XIX. Reinos de Nueva España y Guatemala, coordinado por Laura Machuca Gallegos. México: Publicaciones de la Casa Chata, 2014, pp. 167-192.

Hoberman, Louisa y Susan Socolow. Ciudades y sociedad en Latinoamérica colonial. Buenos Aires: FCE, 1986.

Lucena Giraldo, Manuel. A los cuatro vientos. Las ciudades de la América Hispánica. Madrid: Marcial Pons Ediciones de Historia, 2006.

Lynch, John. Administración colonial española 1782-1810. El sistema de intendencias en el virreinato del Rio de la Plata. Buenos Aires: Eudeba, 1962.

---. "Intendants and Cabildos in the Viceroyalty of La Plata, 1782-1810". The Hispanic American Historical Review, n. ${ }^{\circ}$ 35, 1955, pp. 337-362. DoI: https://doi.org/10.2307/2509526

Martínez Baeza, Sergio. Epistolario de don Nicolás de la Cruz y Bahamonde primer conde de Maule. Santiago: Centro de Investigaciones Diego Barros Arana, 1994.

Molina, Miguel. “Autonomía frente a centralismo. La defensa de los fueros del cabildo de Quito (1782-1798)”. El municipio indiano: relaciones interétnicas, económicas y sociales. Homenaje a Luis Navarro García, coordinado por Manuela García Bernal y Sandra Olivero. Sevilla: Universidad de Sevilla, 2009, pp. 531-546. 
Moore, John. El cabildo en el Perú bajo los Borbones, un estudio de la decadencia y resurgimiento de los gobiernos locales en la Audiencia de Lima. Durham: Duke University Press, 1966.

Morelli, Federica. “Orígenes y valores del municipalismo iberoamericano”. Araucaria: Revista Iberoamericana de Filosofía, Politica, Humanidades y Relaciones Internacionales, n. ${ }^{\circ}$ I8, 2017 , pp. II6-I29.

Navarro García, Luis. Intendencias en América. Sevilla: Servicio de Publicaciones de la Escuela de Estudios Hispanoamericanos, 1959.

Pietschman, Horst. Las reformas borbónicas y el sistema de intendencias en Nueva España. México: FCE, 1996.

Ponce Leiva, Pilar. Certezas ante la incertidumbre. Elite y cabildo de Quito en el siglo XVII. Quito: Abya-Yala, 1998.

Rojas, Beatriz. Cuerpo politico y pluralidad de derechos. Los privilegios de las corporaciones novohispanas. México: CIDE/Instituto Mora, 2007.

---. El municipio libre. Una utopía perdida en el pasado. Los pueblos de Zacatecas 1786-I835. México: Instituto Mora, Colegio de Bachilleres del Estado de Zacatecas, Instituto Cultural de Aguascalientes, 2010.

---. Las instituciones de gobierno y la elite local, Aguascalientes del siglo XVII a la independencia. México: El Colegio de Michoacán, Instituto Mora, 1998.

Serrano, José Antonio. Jerarquía territorial y transición politica. Zamora: El Colegio de Michoacán, Instituto Mora, 200 I.

Vela, Francisco Javier. "Ciudades, villas y lugares: urbanización y jerarquía en la Corona de Castilla del Siglo de Oro". Atas de I Congresso Histórico Internacional As Cidades na História: Populacao, 2012, pp. 193-220.

Zamora, Romina. "Dinámicas de Antiguo Régimen: el gobierno de la república de San Miguel de Tucumán a fines del siglo XVIII". CLARH: Colonial Latin American Historical Review, vol. 17, n. ${ }^{\circ}$, 2008 , pp. 163-188.

Zúñiga, Jean Paul. "Historia de una permanencia. Las elites de Santiago de Chile en el siglo XVIII: familia y poder local". Fronteras de la Historia, vol. 4, I999. DOI: https://doi. org/10.22380/20274688.774. 